\title{
OPTIMIZING PEDESTRIAN-FRIENDLY WALKING PATH FOR THE FIRST AND LAST MILE TRANSIT JOURNEY BY USING THE ANALYTICAL NETWORK PROCESS (ANP) DECISION MODEL AND GIS NETWORK ANALYSIS
}

\author{
Nabilah Naharudin, Mohd. Sanusi S. Ahamad, Ahmad Farhan Mohd. Sadullah \\ School of Civil Engineering, Universiti Sains Malaysia \\ nn15_civ014@student.usm.my
}

KEYWORDS: Pedestrian-Friendly, Path Selection, Geographical Information System, Analytical Network Process

\begin{abstract}
:
Every transit trip begins and ends with pedestrian travel. People need to walk to access the transit services. However, their choice to walk depends on many factors including the connectivity, level of comfort and safety. These factors can influence the pleasantness of riding the transit itself, especially during the first/last mile (FLM) journey. This had triggered few studies attempting to measure the pedestrianfriendliness a walking environment can offer. There were studies that implement the pedestrian experience on walking to assess the pedestrianfriendliness of a walking environment. There were also studies that use spatial analysis to measure it based on the path connectivity and accessibility to public facilities and amenities. Though both are good, but the perception-based studies and spatial analysis can be combined to derive more holistic results. This paper proposes a framework for selecting a pedestrian-friendly path for the FLM transit journey by using the two techniques (perception-based and spatial analysis). First, the degree of importance for the factors influencing a good walking environment will be aggregated by using Analytical Network Process (ANP) decision rules based on people's preferences on those factors. The weight will then be used as attributes in the GIS network analysis. Next, the network analysis will be performed to find a pedestrian-friendly walking route based on the priorities aggregated by ANP. It will choose routes passing through the preferred attributes accordingly. The final output is a map showing pedestrian-friendly walking path for the FLM transit journey.
\end{abstract}

\section{INTRODUCTION}

It is a global concern that mobility in a city should be improved by providing a good transit services for people to commute around a city as well as between their suburban area. Many aspects had been considered to deliver the best quality level of service including a good first/last mile (FLM) journey. FLM refers to the mode of transportation, by walking or cycling around a quarter mile radius to access the transit service (Guerra, Cervero and Tischler, 2012). Every transit trip, in any cities around the world, will definitely begin and end with walking (Ratner and Goetz, 2013; Tilahun et al., 2016). A good FLM environment will simultaneously enhance the pleasantness of using the transit services.

However, pedestrian-friendliness is never been easy to be measured. There is significant increase in studies focusing on it, each applying different methods. There were a few studies that suggested that a good walking environment can be assessed by taking more than one criteria at once into consideration (Lee et al., 2013; Moura, Cambra and Gonçalves, 2017). This is because pedestrian-friendliness can be influenced by many factors (American Association of State Highway and Transportation Officials, 2004; Stockholm City Planning Administration, 2010; Centre for Liveable Cities Singapore and The Seoul Institute, 2016). Therefore, it needs to be assessed simultaneously to optimally measure that pedestrian-friendliness. There is quite a number of studies attempted to spatially analyse the pedestrian-friendliness of a walking environment.
Most of the method used the connectivity and accessibility to various land uses and density of built environments as a measure of pedestrian-friendliness of a walking path. (Carr, Dunsiger and Marcus, 2010; Foda and Osman, 2010; Lwin and Murayama, 2011; Giles-Corti et al., 2014; Murekatete and Bizimana, 2015; Stockton et al., 2016). These studies focuses on the diversity of land uses that can be accessed by the walking path.

There were also studies measured the pedestrian-friendliness of a certain area based on the people's experience obtained by sample survey (Mehta, 2008; Bahari, Arshad and Yahya, 2012; Shojaei and S, 2012; Ariffin and Zahari, 2013; Sutikno and Kurniawan, 2013; Moura, Cambra and Gonçalves, 2017). However, only a few highlighted the possibility of using the people's experience or judgment as an attributes to spatially model a good walking path.

This paper attempts to develop a framework for integrating MCE technique and GIS to find the pedestrian-friendly path for the FLM transit journey. The criteria that influence Malaysian preferences on walking will be included in the analysis. The priorities for each of the criteria derived by the MCE evaluation will be inserted as attributes in the GIS network analysis. The analysis will choose route having good parameters and avoid any risky area which will represent a pedestrian-friendly path for FLM transit journey. 


\section{PEDESTRIAN-FRIENDLY FIRST AND LAST MILE TRANSIT JOURNEY}

FLM can be considered as the first impression for any transit services. It is a part of the services as it covers the first and last mile of a full transit journey. It referred as the access to reach the service itself either by walking or cycling (Guerra, Cervero and Tischler, 2012). The quality of FLM will definitely affect the quality of the transit service (Tilahun et al., 2016). Therefore, it is expected that FLM should always be able to satisfy the public's needs so that they will find commuting by a transit service pleasant.

However, why is it important to provide a good walking environment to the transit commuters? The relevance here is that, walking is very different from driving. It is at a slower pace, thus the pedestrian can be exposed more to the environments such as rain, sun and any possible danger (Funk, 2012). Therefore, the pleasantness of riding the transit services start from the very first mile of the journey. This had led to the emerging of number of researches on the impact of built environments along a walking path to the quality of transit services.

However, there had been a great debate on the coverage distance of the FLM. How long should it be? The most used coverage distance is a half mile or 400 meters. However, it should consider the public's willingness to walk and other factors (American Association of State Highway and Transportation Officials, 2004; Transport For London, 2005; New Zealand Transport Agency, 2009). For example, walking choice can be influenced by the climate where people tend to avoid walking at under the sun as it can be more tiring. They prefer the walking path to have a roof or trees so that they can be sheltered from the sunrays and rain (Shojaei and S, 2012; Zakaria and Ujang, 2015). Other factors influencing the people willingness to walk is the urbanization of the city itself. In Malaysia, there is a vast differences between the two as people will walk up to 600 meters in a rural area as compared to 400 meters in urban area (Azmi, Abdul Karim and Mohd Amin, 2013). This paper however will use 400 meters since the pilot study was conducted in Kuala Lumpur.

\subsection{Factors Influencing the Pedestrian-Friendliness}

It is a fact that people will walk more if they found the environment allows them to walk pleasantly. However, the pedestrian-friendliness can be affected by several factors. This will definitely affect people choice to walk. A good walking environment is always defined by the 3Ds which referred to its design, density and diversity. The first one is the street design. This means that a street design do influence people choice to walk. A good street design allows people to walk to their destination easily. For the FLM of transit service, it is vital for the walking path to have a good access to the station from people's origin. The path should also be continuous so that it will take people directly to access the transit service without making a detour while walking (Cheng and Chen, 2015; Papa and Bertolini, 2015; Sarkar et al., 2015).

The street density referred to the amount of facilities and furniture along the path that will enhance the pleasantness of walking. First is the density of traffic aids facilities such as traffic lights and crossings at the intersection that will enhance the safety of walking (Landis et al., 2001; Guo and Loo, 2013; Karim and Azmi, 2013). It should also has a facilities and furniture that will make the walking path attractive (Giles-Corti et al., 2005; Doyle et al., 2006; Mansor and Said, 2008; Wan Omar, Patterson and Pegg, 2011; Moura, Paulo and Gonçalves, 2014; Chen and Chang, 2015; Jun and Hur, 2015).The street diversity represent various land uses that should have an access to the transit services by the walking path (Brown et al., 2009; Sundquist et al., 2011; Sugiyama et al., 2016). The mixed land uses will support the variety of trip purposes by different people. For example, there are people that will use transit service to go to their workplace, but there are also some that use it for leisure to go for shopping.

\section{GIS NETWORK ANALYSIS}

GIS is considered as the most capable platform in creating the spatial database for the pedestrian data and manipulate the data for analysis and modeling of the pedestrian-friendliness of a walking environment (Schlossberg, Weinstein Agrawal and Irvin, 2007; Colclough, 2009; Lwin and Murayama, 2011; Murekatete and Bizimana, 2015; Naharudin, Ahamad and Sadullah, 2016). It had been used for display purposes the most, but it has capabilities of more than that. The database created on GIS platform can actually be manipulated for analysis purposes including the routing analysis with its network analyst.

GIS network analyst allows the analysis along the route or network dataset to be conducted with the attributes information stored by the database for each spatial dataset. The simple network analysis tools include the service area analysis that will create the catchment area of a facility or centroid based on specified impedance distance using shortest path analysis that implement Djikstra's algorithm, closest facilities analysis that will locate the demand to the nearest facilities possible and more.

\subsection{Shortest Path Analysis}

Finding a shortest path to travel between two points is one of the main purpose in conducting the analysis through a network. This had led to the development of Dijkstra's algorithm that will calculate a shortest path based on the links connected to a node. The algorithm will calculate all possible routes to reach a node and select the shortest one as illustrated in Figure 1.

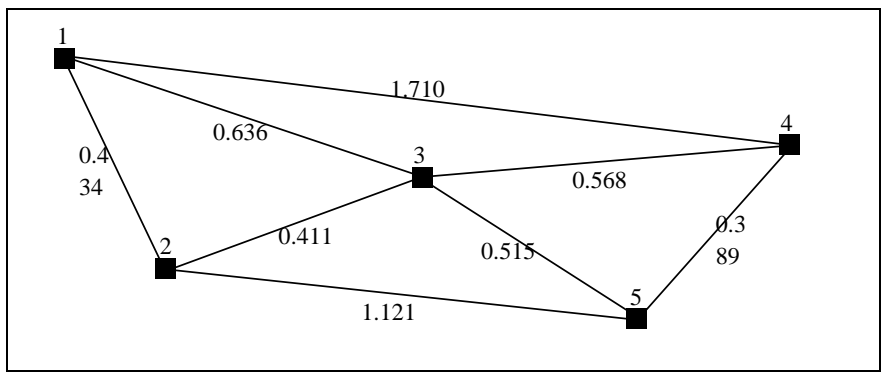

Figure 1: Network used to Find Shortest Path

For example, the analyst needs to solve or find the shortest route to reach node 5 from node 1 . The shortest path will be determined in an iteration process of trial and error. There will be more than one possible routes to reach node 5 from node 1, with each passing different nodes. Therefore, the iteration process will be taking place by testing different node. 
The node having shortest distance to the source will be selected. Then, this node will be included in the analysis and indicated as $n$. The nodes connected to $\mathrm{n}$ which are still not included are then analysed and indicated as $m$. the distance between $m$ and $n$ is given by $d(n m)$. If the sum of distance $n$ and $d(n m)$ is less than dist $(m)$, then $\operatorname{dist}(\mathrm{m})$ is equal to the total of $\operatorname{dist}(\mathrm{n})$ and $\mathrm{d}(\mathrm{nm})$ and $\operatorname{parent}(\mathrm{m})$ is equal to $\mathrm{n}$. This means that if there is a shorter route from the source node to node $m$ via node $n$, then the entry for node $m$ is updated with new total distance with its parent value set to $n$.

First, for the 'After iteration 1' table, the distance from source node 1 is set to 0 and is labelled as ' $\mathrm{Y}$ ' as it is included in the shortest path analysis. The node 1 is connected to nodes 2,3 and 4 . The distance connecting them will be inserted in the distance column. For the second iteration, the shortest distance from any node which are still not included is determined. Now, node 2 is included. It is connected to node 3 . The distance to node 5 via node 3 is larger than the direct distance from node 1 and 4 to node 5 . So, the entry for node 3 via 2 is not changed. In the next iteration, node 3 has the shortest distance to reach node 5. It direct distance to reach node 5 from origin is shorter than other possible routes via node 2 and 4 making entry for both nodes remains the same. But the distance from node 1 to node 5 via node 3 is shorter than via node 2 which is 1.151 . Therefore, the shortest path to reach node 5 from node 1 is via node 3 with a distance of 1.151 .

Table 1: Starting table and tables after each iteration of Dijkstra's algorithm

\begin{tabular}{|l|l|l|l|}
\hline \multicolumn{4}{|c|}{ Starting table } \\
\hline N & Distance & Parent & Included \\
\hline 1 & $\infty$ & & N \\
\hline 2 & $\infty$ & & N \\
\hline 3 & $\infty$ & & N \\
\hline 4 & $\infty$ & & N \\
\hline 5 & $\infty$ & & N \\
\hline
\end{tabular}

\begin{tabular}{|l|l|l|l|}
\hline \multicolumn{4}{|c|}{ After iteration 1 } \\
\hline $\mathrm{N}$ & Distance & Parent & Included \\
\hline 1 & 0 & - & $\mathrm{Y}$ \\
\hline 2 & 0.434 & 1 & $\mathrm{~N}$ \\
\hline 3 & 0.636 & 1 & $\mathrm{~N}$ \\
\hline 4 & 1.710 & 1 & $\mathrm{~N}$ \\
\hline 5 & $\infty$ & & $\mathrm{N}$ \\
\hline \multicolumn{4}{|l}{} \\
\hline
\end{tabular}

\begin{tabular}{|l|l|l|l|}
\hline \multicolumn{4}{|c|}{ After iteration 2} \\
\hline $\mathrm{N}$ & Distance & Parent & Included \\
\hline 1 & 0 & - & $\mathrm{Y}$ \\
\hline 2 & 0.434 & 1 & $\mathrm{Y}$ \\
\hline 3 & 0.636 & 1 & $\mathrm{~N}$ \\
\hline 4 & 1.710 & 1 & $\mathrm{~N}$ \\
\hline 5 & 1.555 & 2 & $\mathrm{Y}$ \\
\hline
\end{tabular}

\begin{tabular}{|l|l|l|l|}
\hline \multicolumn{4}{|c|}{ After iteration 3} \\
\hline $\mathrm{N}$ & Distance & Parent & Included \\
\hline 1 & 0 & - & $\mathrm{Y}$ \\
\hline 2 & 0.434 & 1 & $\mathrm{~N}$ \\
\hline 3 & 0.636 & 1 & $\mathrm{Y}$ \\
\hline 4 & 1.710 & 1 & $\mathrm{~N}$ \\
\hline 5 & 1.151 & 3 & $\mathrm{Y}$ \\
\hline
\end{tabular}

Shortest path analysis had been used many times in routing problem especially for navigating purposes where one needs to find a shortest route possible to reach certain destination. It also offers great contribution to emergency response problems such as deporting fire trucks and ambulance.

For pedestrian study, this analysis had been useful in finding shortest possible walking routes for pedestrian to reach their destination. However, since walking can be influence by many factors, many studies attempted to improvise the Dijkstra's algorithm to find optimal walking path for pedestrian. This will be discussed further in the next section.

\subsection{Optimal Path Selection with Improvised Dijkstra's algorithm}

One of the algorithms used by the network analysis in GIS is Dijkstra's algorithm or graph theory that will aid in finding the optimal routes between two points. This algorithm will find the shortest path that satisfies the purpose of the analysis. For example, a good route to travel by walking should have a shelter to enhance the pleasantness of walking. Therefore, the analyst will choose the route having the shelter regardless the distance to reach the destination as illustrated in Figure 2.

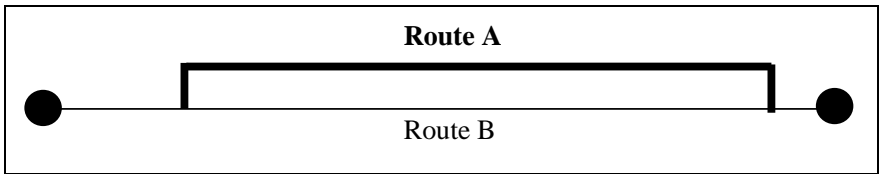

Figure 2: Optimal Route Selection by GIS using Djikstra's Algorithm

GIS network analysis had been implemented many times previously in measuring the connectivity and accessibility of a walking path. It had been used to measure the access from jobs area to public transportation system in Melbourne (Giles-Corti et al., 2014). This study used jobs and residential area as the demand for the public transportation. The accessibility from the demand was then measured based on the time taken by walking from the transits along the pedestrian path available in the city.

There is also a possibility of making used of the catchment area created by the network analysis to measure the accessibility of the transit stops. This kind of study aims to understand the demand that can be covered by the transit stops within walking distance. In example, in Aleaxandria, they measured the accessibility of the transit stops based on ratio of the total length of footpath in the catchment area in respect to the 400 meters walking distance (Foda and Osman, 2010). It produces an isochrones maps of the accessibility of the bus stops there.

\section{ANALYTICAL NETWORK PROCESS DECISION MODEL}

Multicriteria decision analysis is the best technique that can deal with multiple criteria at one time. It had been used many times in making a decision for various planning purposes. The method will rate or rank the criteria according to their degree of importance. One of the technique to derive the priorities is the pairwise comparison. This technique requires the criteria to be rated in pair (Malczewski, 2006; Greene et al., 2011). Therefore, rather than making judgment for all criteria at once, the criteria will be paired and rated.

\subsection{Concept of the Analytical Network Process}

Pairwise comparison method can be conducted by using two different techniques which are the Analytical Hierarchical Process (AHP) and Analytical Network Process (ANP). Like the name suggested, the former will rate the criteria hierarchically while the latter uses the network or interdependencies between the criteria regardless of their hierarchy as illustrated in Figure 3. Its solving mechanism is actually closer to the reality. 


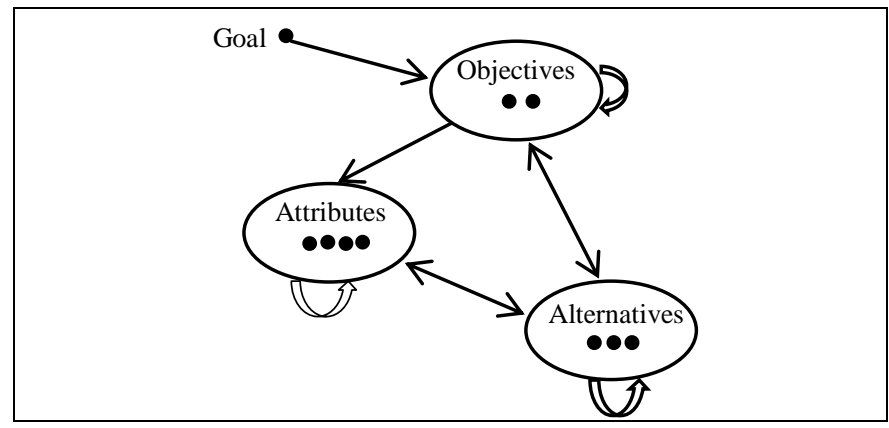

Figure 3: Structure of ANP Network represent the origin (Source node) or destination (Sink node) of the influence (Saaty and Vargas, 2006). ANP allows the inner and outer dependencies between the elements in the network. The priorities for each of the criteria will be synthesized by using supermatrix as shown in Figure 4. The priorities will be aggregated by multiplying the values in an unweighted supermatrix (rating obtained during pairwise comparison) with the eigenvectors for each of the cluster to form the weighted supermatrix. The values in this supermatrix will be normalized by using formula in equation 1 to derive the priorities for the criteria.
(1)

ANP network consist of clusters containing the nodes and links

signifying the dependencies between the nodes. The nodes can

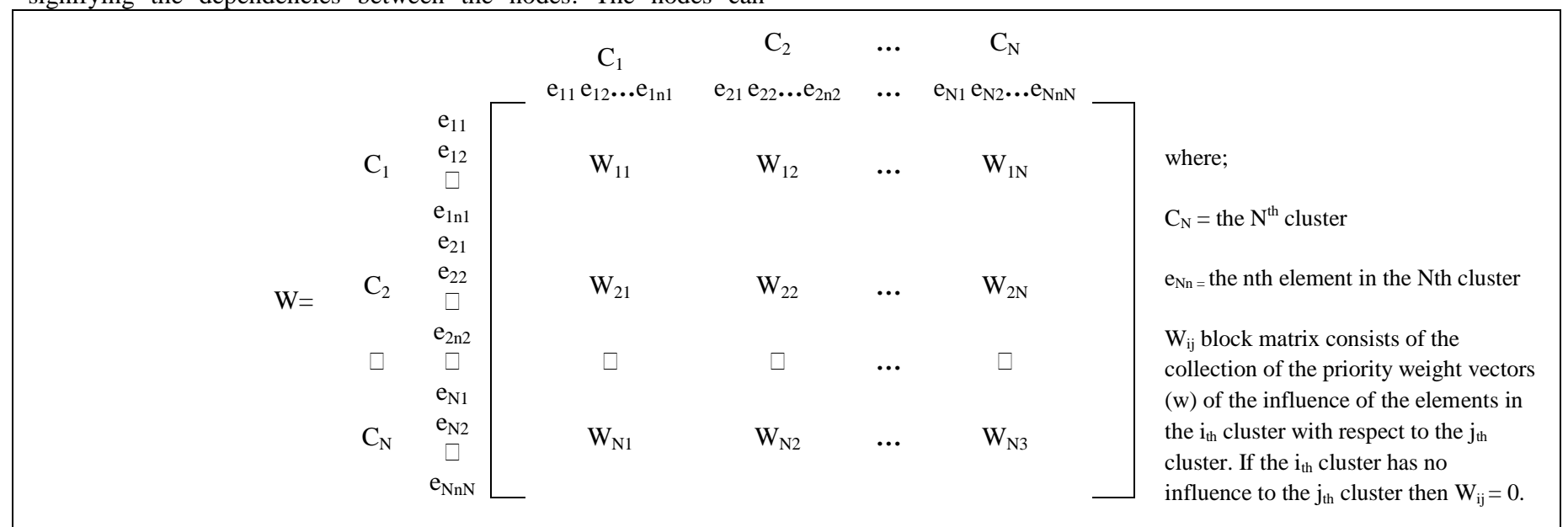

Figure 4: Supermatrix of ANP

\subsection{ANP in Pedestrian-Friendliness Studies}

ANP is still very new in transportation studies. However, few studies had been conducted to assess the pedestrian-friendliness by using ANP decision model. It is a good method since walking can be influenced by many criteria at once, and they depends on each other too, as discussed previously.

It had been used to rank the criteria preferred by the local citizens of Taipei on the pedestrian-friendliness environment they wished for a MRT stations to have (Wey, 2014). The study use ANP to understand which of the technical requirements outlined by the local council to build a metro station are preferred by the public. The extension of the studies involved siting for the best pedestrian-friendly MRT stations there (Wey, 2015; Wey, Zhang and Chang, 2016).

ANP had also been applied in studies done in Seoul to assess the walkability of two stations there which are Seoul station and Jongno3 station (Leather et al., 2011). The studies conducted to measure the stations' level of service based on its, safety, connectivity and street design. The priorities for each criteria were visualized in map and they used weightage linear combination (WLC) to calculate the total walkability score.

\section{PEDESTRIAN-FRIENDLY PATH SELECTION BY INTEGRATING ANP MODEL AND GIS ANALYSIS}

The walkability of a footpath depends on the parameters that are located on it. Therefore, it is essential to measure the walkable route according to the specific parameters. In this study, the analyst will search for an optimal route from a station to reach a possible destination. The optimal route does not necessarily be the shortest path, rather it should pass through the preferred parameters and ignore the avoided parameters.

In this study, the optimal routes will be determined by using the closest facilities analysis in ArcGIS environment. It will utilize the attributed parameter network dataset that had been built earlier and manipulate the Dijkstra's algorithm in searching for a route according to preferences set on the network dataset.

\subsection{Aggregating Priorities for Parameters with ANP}

For this study, seven criteria that influence the pedestrian-friendliness were selected based on the 3Ds described previously. They were then will be represented by at least two measurable parameters of the built environments along the path on ground for the analysis in GIS environment. 




Figure 5: ANP Model showing the Dependencies between the Criteria

The seven criteria will be the control criteria where their priorities will affect the degree of importance of the measurable parameters. Both criteria and their parameters were represented as a node in ANP model as illustrated in Figure 5. The seven criteria was put in a cluster named 'Control Criteria'. The measurable parameters were put in their respective 'Control Criteria' clusters. The parameters were then linked by an arrow based on their dependencies. The degree of importance for each criteria are aggregated by using supermatrix based on their rating gained during the pairwise comparison. The rating are translated into a set of priorities as shown in Table 2. The priorities will be the weighing factors that influence the path choice for the analysis. The analysis will choose path that contains parameter with a greater value of priorities for the preferred parameters. In contrary, it will choose a path that has parameter with a smaller value of priorities for the risky parameters (parameters representing perceived security).

Table 2: Aggregated Priorities for each Sub-criteria

\begin{tabular}{llc} 
Criteria & Sub-Criteria & Priorities \\
\hline Connectivity & Bus/Taxi stops & 0.071503 \\
& Commercial area & 0.14102 \\
& Business area & 0.121797 \\
& Residential area & 0.304306 \\
\hline Conspicuous & Signage showing name & 0.07623 \\
& Signage showing direction & 0.597091 \\
& Signage showing distance & 0.238905 \\
\hline Conviviality & Food and beverages vendors & 0.113673 \\
& Public parks & 0.339327 \\
& Resting points & 0.153125 \\
\hline Shelter & Row of Roof & 0.444867 \\
& Row of Trees & 0.223017 \\
\hline Convenience & Walking time & 0.419746 \\
& Walking distance & 0.30348 \\
\hline Traffic safety & Presence of crossings & 0.176551 \\
& Presence of traffic lights & 0.305838 \\
\hline Perceived & Proximity to abandon area & 0.146718 \\
security & Proximity to construction sites & 0.226868 \\
& Proximity to public alley & 0.191901
\end{tabular}

\subsection{GIS Network Analysis with Attributed Parameter Data Model}

ANP-derived weight will be used to indicate the walkability of an area in GIS model. This explains the term 'Spatial Walkability Index Model'. Instead of displaying the criteria with their weight on the map, it can be included as the attributes of the criteria in the analysis. The criteria datasets will be inserted as an attributed parameter for the network dataset. The attributed parameter will aid the path choice the analyst can made. The attribute can be set as either preferences or avoidance based on their priorities aggregated by ANP.

Then, a network dataset is created by using the pedestrian network data with the cost of traversing each link specified as the distance between the two nodes at either end. A junction on the routes which includes any intersection of links is designated a node in the network dataset. These nodes, as noted previously, will allow any type of turn to be done during the later analysis.

The pedestrian-friendly FLM transit journey could be established by using the analysis on the impedance either the distance or time traveled through the network from demand points to the central facility (transit station). The tool 'OD Cost Matrix' on ArcGIS is used to generate the optimal route to and fro the transit station, within the 400 meters from it.

OD Cost Matrix defined as the analysis to find optimal route from an origin to reach specified destination. It is the best representation of finding optimal route, by applying the Djikstra's algorithm of the shortest path analysis. But, it will take the factors influencing the route choice into consideration.

During the analysis, the weight will become decisive factors when the analyst chooses a better route to travel on based on the set-up restrictions. The analysis will choose route according to the attributed parameter they encounter to reach certain point from the transit station. The chosen path represents the pedestrian-friendly walking routes to access the transit stations as shown in Figure 6. 


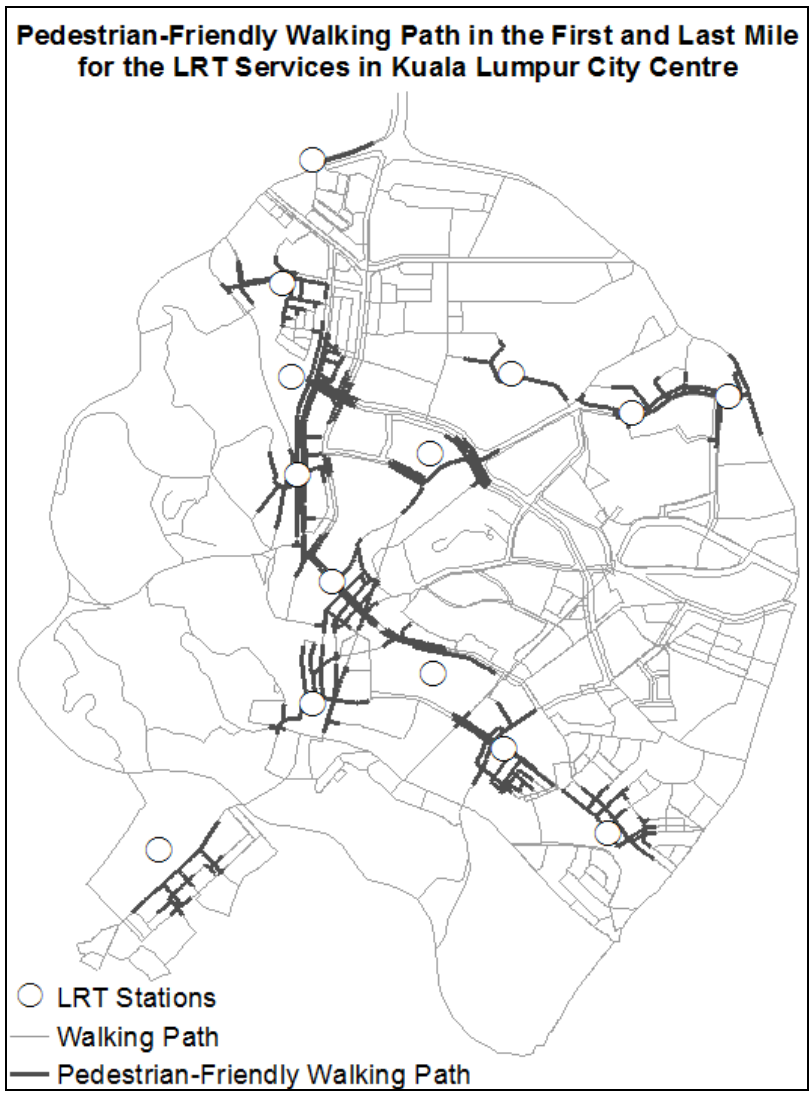

Figure 6: Map of Pedestrian-Friendly First/Last Mile Transit Route around LRT Stations

Based on the map, almost all walking path within the station's catchment area were selected as a pedestrian-friendly walking path. This shows that the LRT services in KL offers a good walking environment for their commuters. However, there were few walking path that are not chosen probably because of their connectivity to the risky area. With this map pointing those path, the local authority or planners can carefully think on how to tackle the issue and make the path more friendly. For the pedestrian or LRT riders, they can use this map as a guide on which path should they walk on to access the LRT services so that their whole journey from the very first to the last mile will be pleasant, comfortable and safe.

\section{CONCLUSION}

This ongoing study aims to develop a spatial model to support a research on assessing the walkability of the existing transit stations in Kuala Lumpur central area. The study focuses on the 400 meters catchment area from each station which the optimal distance people is willing to walk. The built environment in the catchment area will be the determining factors for the pedestrian-friendliness of the stations. They will be represented in the spatial environment as measurable parameters so that they can be modeled with the footpath network in the city. This will produce an attributed parameter network dataset that aid in analyzing the walkability of each station. The analysis will use GIS network analyst capability of choosing route having preferable criteria and avoiding threatening factors that influence people's choice to walk. Each of the attributes has their own degree of importance as aggregated by the ANP decision rules. The final output of this study is a map showing pedestrian-friendly path in each station's catchment area. The map can be used as a reference of the current pedestrianfriendliness of the transit services. It can be used as a basis to improve the level of services by planning for more built environments along the walking route. Then, the analysis can be conducted again to analyse the improvement made when more built environments are built (maybe there will be more pedestrianfriendly walking path around the transit station). In future, the framework can be improved by adding other factors influencing walking and to suit the condition of the walking itself.

\section{REFERENCES}

American Association of State Highway and Transportation Officials (2004) Guide for the Planning, Design, and Operation of Pedestrian Facilities. Washington DC: American Association of State Highway and Transportation Officials.

Ariffin, R. N. R. and Zahari, R. K. (2013) 'Perceptions of the Urban Walking Environments', Procedia - Social and Behavioral Sciences. Elsevier B.V., 105, pp. 589-597. doi: 10.1016/j.sbspro.2013.11.062.

Azmi, D. I., Abdul Karim, H. and Mohd Amin, M. Z. (2013) 'Walking Behavior of Urban and Rural Streets', Journal of Asian Behavioral Studies, 11(July 2013), pp. 97-110.

Bahari, N. I., Arshad, A. K. and Yahya, Z. (2012) 'Pedestrians' perception of the sidewalk facilities in Kuala Lumpur's commercial areas', International Sustainability and Civil Engineering Journal, 1(2), pp. 28-36.

Brown, B. B. et al. (2009) 'Mixed land use and walkability: Variations in land use measures and relationships with BMI, overweight, and obesity', Health and Place. Elsevier, 15(4), pp. 1130-1141. doi: 10.1016/j.healthplace.2009.06.008.

Carr, L. J., Dunsiger, S. I. and Marcus, B. H. (2010) 'Walk Score??? as a global estimate of neighborhood walkability', American Journal of Preventive Medicine. Elsevier Inc., 39(5), pp. 460-463. doi: 10.1016/j.amepre.2010.07.007.

Centre for Liveable Cities Singapore and The Seoul Institute (2016) Walkable and Bikeable Cities: Lessons from Seoul and Singapore. 1st edn. Edited by C. Grace. Singapore: Centre for Liveable Cities, The URA Centre.

Chen, J. and Chang, Z. (2015) 'Rethinking urban green space accessibility: Evaluating and optimizing public transportation system through social network analysis in megacities', Landscape and Urban Planning. Elsevier B.V., 143, pp. 150-159. doi: 10.1016/j.landurbplan.2015.07.007.

Cheng, Y. H. and Chen, S. Y. (2015) 'Perceived accessibility, mobility, and connectivity of public transportation systems', Transportation Research Part A: Policy and Practice. Elsevier 
Ltd, 77, pp. 386-403. doi: 10.1016/j.tra.2015.05.003.

Colclough, J. G. (2009) 'Modelling Pedestrian Accessibility Using GIS Techniques to Assess Development Sustainability', European Transport Conference, p. 9 pp.

Doyle, S. et al. (2006) 'Active community environments and health - The relationship of walkable and safe communities to individual health', Journal of the American Planning Association, 72(1), pp. 19-31. doi: 10.1080/01944360608976721.

Foda, M. and Osman, A. (2010) 'Using GIS for Measuring Transit Stop Accessibility Considering Actual Pedestrian Road Network', Journal of Public Transportation, 13(Tcrp 1996), pp. 23-40.

Available at: http://www.nctr.usf.edu/jpt/pdf/JPT13-4Foda.pdf. Funk, C. (2012) Walkability of transit-oriented development: Evaluating the pedestrian environment of Metro Vancouver's. Kingston.

Giles-Corti, B. et al. (2005) 'Increasing walking: How important is distance to, attractiveness, and size of public open space?', American Journal of Preventive Medicine, 28(2 SUPPL. 2), pp. 169-176. doi: 10.1016/j.amepre.2004.10.018.

Giles-Corti, B. et al. (2014) 'How Walkable is Melbourne? The Development of a Transport Walkability Index For Metropolitan Melbourne. Place, Health and Liveability Research Program'.

Greene, R. et al. (2011) 'GIS-Based Multiple-Criteria Decision Analysis', Geography Compass, 5(6), pp. 412-432. doi: 10.1111/j.1749-8198.2011.00431.x.

Guerra, E., Cervero, R. and Tischler, D. (2012) 'Half-Mile Circle Does It Best Represent Transit Station Catchments?', Transportation Research Record, 2276(August), pp. 101-109. doi: 10.3141/2276-12.

Guo, Z. and Loo, B. P. Y. (2013) 'Pedestrian environment and route choice: Evidence from New York City and Hong Kong', Journal of Transport Geography, 28, pp. 124-136. doi: 10.1016/j.jtrangeo.2012.11.013.

Jun, H. J. and Hur, M. (2015) 'The relationship between walkability and neighborhood social environment: The importance of physical and perceived walkability', Applied Geography.

Elsevier Ltd, 62, pp. 115-124. doi: 10.1016/j.apgeog.2015.04.014. Karim, H. A. and Azmi, D. I. (2013) 'Convenience and Safety of Walking Experience in Putrajaya Neighbourhood Area', Procedia - Social and Behavioral Sciences. Elsevier B.V., 101, pp. 318-327. doi: 10.1016/j.sbspro.2013.07.206.

Landis, B. et al. (2001) 'Modeling the Roadside Walking Environment: Pedestrian Level of Service', Transportation Research Record: Journal of the Transportation Research Board, pp. 82-88. doi: 10.3141/1773-10.

Leather, J. et al. (2011) 'Walkability and Pedestrian Facilities in Asian Cities State and Issues', Asian Development Bank Sustainable Development Working Paper Series, (17), p. 69.

Lee, S. S. et al. (2013) 'A New Approach for the Evaluation of the
Walking Environment', International Journal of Sustainable Transportation, 7(December 2012), pp. 238-260. doi: $10.1080 / 15568318.2013 .710146$

Lwin, K. K. and Murayama, Y. (2011) 'Modelling of urban green space walkability: Eco-friendly walk score calculator', Computers, Environment and Urban Systems. Elsevier Ltd, 35(5), pp. 408420. doi: 10.1016/j.compenvurbsys.2011.05.002.

Malczewski, J. (2006) 'Decision Analysis for Collaborative GIS', Collaborative geographic information systems, p. 167.

Mansor, M. and Said, I. (2008) 'Green Infrastructure Network as Social Spaces for Well-Being of Urban Residents in Taiping, Malaysia', Environmental Research, (May), pp. 28-30.

Mehta, V. (2008) 'Walkable streets: pedestrian behavior, perceptions and attitudes', Journal of Urbanism: International Research on Placemaking and Urban Sustainability, 1(3), pp. 217-245. doi: 10.1080/17549170802529480.

Moura, F., Cambra, P. and Gonçalves, A. B. (2017) 'Measuring walkability for distinct pedestrian groups with a participatory assessment method: A case study in Lisbon', Landscape and Urban Planning, 157, pp. 282-296. doi: 10.1016/j.landurbplan.2016.07.002.

Moura, F., Paulo, C. and Gonçalves, A. (2014) 'IAAPE Pedestrian Accessibility and Attractiveness Assessment Tool when planning for Walkability', CITTA 7th Annual Conference \& COST TU1002 Final Conference: BRIDGING THE IMPLEMENTATION GAP OF ACCESSIBILITY INSTRUMENTS AND PLANNING SUPPORT SYSTEMS, p. 18.

Murekatete, R. M. and Bizimana, J. P. (2015) 'A GIS-based Approach for Developing Urban Walkability Indices: The Case of Kigali City, Rwanda', Geo Tech Rwanda 2015, pp. 1-7.

Naharudin, N., Ahamad, M. S. S. and Sadullah, A. F. M. (2016) 'GIS Data Collection for Pedestrian Facilities and Furniture Using MAPinr for Android', XLII(October), pp. 89-95. doi: 10.5194/isprs-archives-XLII-4-W1-89-2016.

New Zealand Transport Agency (2009) 'Pedestrian Planning and Design Guide Chapter 4 Community Walkability’, pp. 1-6.

Papa, E. and Bertolini, L. (2015) 'Accessibility and TransitOriented Development in European metropolitan areas', Journal of Transport Geography. Elsevier Ltd, 47, pp. 70-83. doi: 10.1016/j.jtrangeo.2015.07.003.

Ratner, K. A. and Goetz, A. R. (2013) 'The reshaping of land use and urban form in Denver through transit-oriented development', Cities. Elsevier Ltd, 30(1), pp. 31-46. doi: 10.1016/j.cities.2012.08.007.

Saaty, T. L. and Vargas, L. G. (2006) DECISION MAKING WITH THE ANALYTIC NETWORK PROCESS: economic, political, social and technological applications with benefits, oportunities, costs and risks.

Sarkar, C. et al. (2015) 'Exploring associations between urban 
green, street design and walking: Results from the Greater London boroughs', Landscape and Urban Planning. Elsevier B.V., 143, pp. 112-125. doi: 10.1016/j.landurbplan.2015.06.013.

Schlossberg, M., Weinstein Agrawal, A. and Irvin, K. (2007) 'An Assessment of GIS-Enabled Walkability Audits', Journal of Urban and Regional Information Systems Association, 19(1), pp. $5-11$.

Shojaei, S. and S, M. K. M. (2012) 'Preferences for Pedestrian Walkways in Tropical Urban Neighbourhoods of Kuala Lumpur, Malaysia', 6(3), pp. 477-486.

Stockholm City Planning Administration (2010) 'The walkable city: Stockholm city plan', (March), p. 88. Available at: http://international.stockholm.se/Future-Stockholm/Stockholm-

City-Plan/.

Stockton, J. C. et al. (2016) 'Development of a novel walkability index for London, United Kingdom: cross-sectional application to the Whitehall II Study', BMC Public Health. BMC Public Health, 16(1), p. 416. doi: 10.1186/s12889-016-3012-2.

Sugiyama, T. et al. (2016) 'Residential proximity to urban centres, local-area walkability and change in waist circumference among Australian adults', Preventive Medicine. Elsevier Inc., 93, pp. 3945. doi: 10.1016/j.ypmed.2016.09.028.

Sundquist, K. et al. (2011) 'Neighborhood walkability, physical activity, and walking behavior: The Swedish Neighborhood and Physical Activity (SNAP) study', Social Science and Medicine. Elsevier Ltd, 72(8), pp. 1266-1273. doi: 10.1016/j.socscimed.2011.03.004.

Sutikno, F. R. and Kurniawan, E. B. (2013) 'Walkability and Pedestrian Perceptions in Malang City Emerging Business Corridor', Procedia Environmental Sciences. Elsevier B.V., 17, pp. 424-433. doi: 10.1016/j.proenv.2013.02.056.

Tilahun, N. et al. (2016) 'Transit use and the work commute: Analyzing the role of last mile issues', Journal of Transport Geography. Elsevier B.V., 54, pp. 359-368. doi: 10.1016/j.jtrangeo.2016.06.021.

Transport For London (2005) 'Transport for London: Improving walkability', (September). Available at: http://www.gtkp.com/assets/uploads/20091126-003242-7483improving-walkability2005.pdf.

Wan Omar, W. R., Patterson, I. and Pegg, S. (2011) 'Healthy lifestyle: Promoting walking behaviour in Kuala Lumpur, Malaysia', World Journal of Management, 3(1), pp. 109-123. Available http://espace.library.uq.edu.au/view/UQ:239710\#.VnN4HbBxoqw. mendeley.

Wey, W. (2014) 'The Application of Dynamic Network Process to Environment Planning Support Systems', 8(8), pp. 914-917.

Wey, W.-M., Zhang, H. and Chang, Y.-J. (2016) 'Alternative transit-oriented development evaluation in sustainable built environment planning', Habitat International. Elsevier Ltd, 55, pp. 109-123. doi: 10.1016/j.habitatint.2016.03.003.
Wey, W. M. (2015) 'Smart growth and transit-oriented development planning in site selection for a new metro transit station in Taipei, Taiwan', Habitat International. Elsevier Ltd, 47, pp. 158-168. doi: 10.1016/j.habitatint.2015.01.020.

Zakaria, J. and Ujang, N. (2015) 'Comfort of Walking in the City Center of Kuala Lumpur', Procedia - Social and Behavioral Sciences. Elsevier B.V., 170, pp. 642-652. doi: 10.1016/j.sbspro.2015.01.066. 